\title{
Elbow Heterotopic Ossification Excision in Patients with Worker's Compensation
} Claims

\begin{abstract}
Keywords: Heterotopic ossification; Worker's compensation; Elbow contracture

Abstract

The effect of worker's compensation claims following the surgical management of symptomatic heterotopic ossification (HO) about the elbow has not previously been evaluated. The purpose of this study is to report on a consecutive series of patients with $\mathrm{HO}$ about the elbow. and to compare the results of surgical treatment and a standardized postoperative rehabilitation regimen, with regards to the presence of a worker's compensation claim. A retrospective review of all patients treated operatively for $\mathrm{HO}$ of the elbow at a single institution was performed. Forty-six elbows with $\mathrm{HO}$ treated surgically were identified. Seventeen of the 46 elbows (37\%) had workers' compensation claims at the time of surgery. Other than gender $(\mathrm{p}=0.007)$, there was no statistical difference in patient demographics or medical history. There was no statistical difference in postoperative flexion-extension arc between the two groups ( $p>0.05)$. There was a $17 \%(8 / 46)$ postoperative complication rate, however there was no difference in frequency of complications between groups (Worker's Comp: $18 \%$ vs. Non-Worker's Comp: 17\%; $\mathrm{p}=0.97)$. Surgical management combined with postoperative $\mathrm{HO}$ prophylaxis and a regimented rehabilitation program is an effective treatment for patients with heterotopic ossification of the elbow and workers compensation claims did not adversely affect the postoperative range of motion arc or complications.
\end{abstract}

\section{Introduction}

Multiple previous studies have established that patient's with worker's compensation claims, have higher rates of postoperative noncompliance, longer return to work times, and lower validated outcome scores after variety different orthopaedic treatments [16]. Specific to some shoulder and elbow disorders, it has been demonstrated that worker's compensation patients have poorer outcomes [1,3,6-9]. The effect of worker's compensation on outcome following surgical excision of heterotopic ossification (HO), or the abnormal formation of mature lamellar bone within extra skeletal soft tissues where bone does not exist, about the elbow has not been previously investigated $[10,11]$.

The formation of heterotopic ossification can result from a variety of local and systemic insults. Past research has demonstrated that patients who sustain direct trauma, central nervous system trauma, and thermal burns are at an increased risk for development of HO [11-14]. The elbow is one of the most common sites affected by heterotopic ossification, and in fact is the most common site for patients with thermal burns [15-18]. Most cases of HO about the elbow are localized and run a benign course without significant longterm symptoms or permanent impairment, thus the true incidence may be under reported in the literature [18]. However, extensive HO of the elbow can lead to clinically relevant contractures, and rarely complete ankylosis of the joint [19].

The purpose of this study is to evaluate the effects of a worker's

\section{Journal of}

Orthopedics \& Rheumatology

\section{Dane Salazar ${ }^{1 *}$, Brian Hill ${ }^{1}$, Heidi I srael ${ }^{1}$, Bayan Aghdasi $^{2}$, Andrew Golz BS ${ }^{3}$ and Guido Marra ${ }^{4}$}

${ }^{1}$ Department of Orthopaedic Surgery, Saint Louis University School of Medicine, USA

${ }^{2}$ Orthopaedic Surgery Department, Methodist Hospital, USA

${ }^{3}$ Department of Orthopaedics, Loyola University, USA

${ }^{4}$ Orthopaedic Surgery Department, Northwestern University, USA

*Address for Correspondence

Dane Salazar MD, Division of Shoulder and Elbow Surgery, Department of Orthopaedic Surgery and Rehabilitation, Loyola University Health System, 2160 South First Ave, Maywood IL 60153; Email: dsalazar@lumc.edu

Submission: 25 January, 2018

Accepted: 26 February, 2018

Published: 05 March, 2018

Copyright: ( $) 2018$ Salazar D, et al. This is an open access article distributed under the Creative Commons Attribution License, which permits unrestricted use, distribution, and reproduction in any medium, provided the original work is properly cited.

compensation claims on the results of the surgical treatment of patients with symptomatic $\mathrm{HO}$ about the elbow. Our null hypothesis is that there will be no difference between outcomes in patients with or without worker's compensation claims following surgery.

\section{Materials and Methods}

After institutional review board approval (205239030413), retrospective analysis of medical records for all patients treated for heterotopic ossification of the elbow with surgical excision of ectopic bone were identified between September 1999 and February 2012. All surgeries were performed on an inpatient basis at a Level I Trauma Center and Academic by a single shoulder and elbow surgeon. The indications for surgery included painful and/or restricted range of motion for all patients. Preoperative radiographs and computed tomography scans were obtained on each subject. The diagnosis and evaluation of the maturation of $\mathrm{HO}$ was established using orthogonal views on plain elbow radiographs (Figure 1). Computed tomography

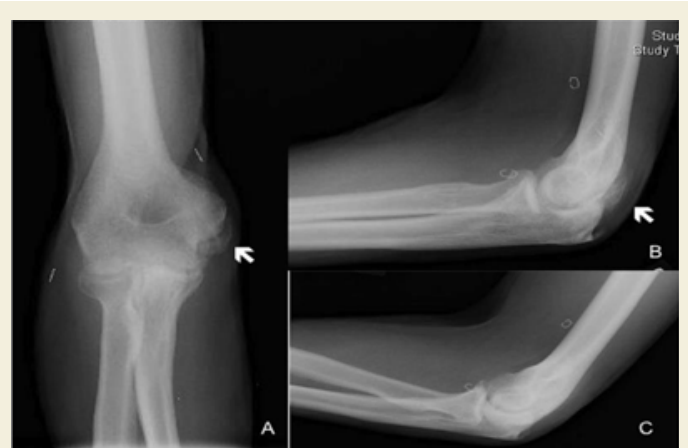

Figure 1: X-rays of the right elbow of a patient with posteromedial heterotopic ossification. A) Anterior-Posterior View B) Lateral View C) Oblique view. The black arrows indicate the mature ectopic bone. 
Citation: Salazar D, Hill B, Israel D, Aghdasi B, Andrew Golz BS, et al. Elbow Heterotopic Ossification Excision in Patients with Worker's Compensation Claims. J Orthopedics Rheumatol. 2018; 5(1): 6.

was performed to establish the relationship between the ectopic bone and the neurovascular structures and for further preoperative planning (Figure 2). Patient demographic data, including age, type of medical insurance, gender, mechanism of injury, history of tobacco usage, and pre-existing medical conditions, were recorded and used for comparisons. Patients with a worker's compensation claim were compared to those patients without a claim.

These patients included in this study have previously been reviewed but not specifically evaluated for the effects of workers compensation claims in a previously published study [20].

\section{Surgical technique}

All surgeries were performed under general anesthesia with an indwelling interscalene catheter to aid with pain control. The surgical approaches were dependent on the location of burn scar, previous incisions, skin condition and extent of heterotopic ossification. A combination of rongeurs, osteotomes and a motorized burr were used to resect ectopic bone down to the level of the joint. The collateral ligaments were identified and protected as needed. After removal of the $\mathrm{HO}$, intraoperative range of motion in the flexion-extension arc was recorded and as necessary and capsular release or capsulectomy was performed to gain additional range of motion. All intraoperative ranges of motion were measured using a sterile goniometer.

The joint was then irrigated and bleeding cancellous bone surfaces were covered with bone wax to minimize postoperative hematoma and/ or recurrence of heterotopic bone. Anterior subcutaneous transposition of the ulnar nerve was performed when clinically indicated. Drains were placed; the muscle fascia and skin were closed. The limb was placed into a bulky dressing in with the arm in extension.

\section{Postoperative management \& prevention}

All patients had their bulky dressing and drains discontinued on the second postoperative day. After removal of the drains, patients were started on continuous passive motion (CPM) machines (Kinetect 6080, Paterson Medical, Warrenville, IL, USA) for 12 hours per day. The indwelling interscalene anesthesia catheters assisted with pain control in the immediate postoperative period. The catheters were discontinued 24 hours prior to discharge to ensure the patients had adequate pain control on an oral narcotic regimen and could tolerate

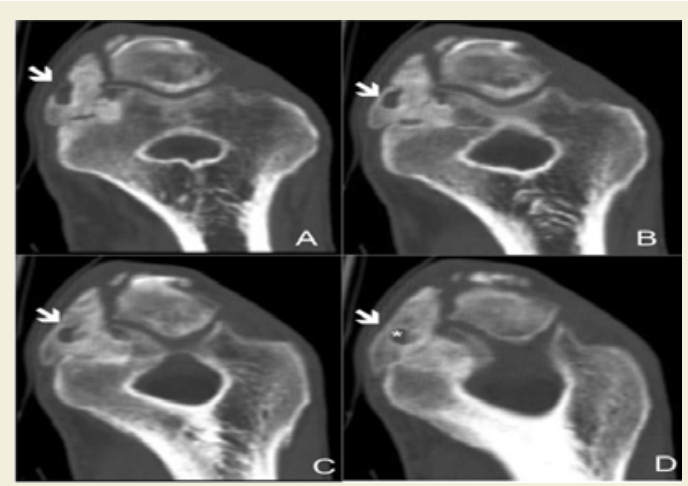

Figure 2: Computed tomography scan of the right elbow of a patient. A, B, $C, D$ represent sequential coronal slices at the level of the cubital tunnel. The white arrows indicate the ectopic bone surrounding the ulnar nerve. The white "*" on cut D represents the area occupied by the ulnar nerve. the passive range of motion therapy. Patients were then discharged home with a home CPM device and the regimen was continued for 2 weeks post-operatively. At discharge, all patients were accompanied by a representative of the CPM device manufacturer to ensure that all machines had been delivered and that the patient understood how to utilize the machine properly.

Two weeks post-operatively, patients were seen in the outpatient office to perform a wound check, remove sutures, and measure their range of motion. All measurements of patient's range of motion were performed by the senior author with the use of a goniometer, to maximize the reliability and reproducibility. At this point, therapist guided active, active assisted, and passive range of motion were begun 5 times per week. The CPM was continued but decreased to 6 hours per day. Six weeks after surgery, the CPM machines were discontinued completely and therapist guided physical therapy was reduced to 3 times per week. At twelve weeks, the patients were discharged from therapy and given a home therapy regimen that included simple range of motion exercises.

For prevention of $\mathrm{HO}$ recurrence, all subjects underwent a sixweek course of oral indomethacin, $75 \mathrm{mg}$ per day. In three patients, non-steroidal anti-inflammatory medications were contraindicated secondary to a known drug allergy. Thus, radiation was substituted for indomethacin. They were treated with a one-time dose of radiation therapy ( $700 \mathrm{cGy}$ ) within 48 hours after surgery. Patients were called weekly for the first four weeks by either a resident physician or clinical nurse on the research team to ensure compliance with the $\mathrm{CPM}$ regimen, physical therapy, and $\mathrm{HO}$ prophylaxis.

\section{Statistical analysis}

Descriptive statistics were performed. Nominal variables were compared using a Chi square test or Fisher's exact test when appropriate. Observed differences between preoperative and postoperative ranges of motion and between patients' worker's compensation and nonworker's compensation were determined with independent $t$-tests or a Mann Whitney non-parametric test when sample size was small. Paired t-tests analyzed differences at each time for each of the two groups. Comparison of continuous variables utilized a regression analysis. SPSS version 20.0 was used; a $p$ value of $<0.05$ was considered significant.

\section{Results}

Thirty-nine patients (46 elbows) were identified that met inclusion criteria. Thirty-two men and 14 women had an average age of 41 (range, 19-71 years), with 16 elbows sustaining burns, 29 traumatic, and 1 a closed head injury. The right elbow was involved $57 \%(26 / 46)$ of the time and the left elbow $43 \%(20 / 46)$, with 7 of the $39(18 \%)$ patients having bilateral involvement. For the burn patients, there were 14 thermal burns and 2 chemical burns. The mean body surface area affected was $57.7 \%$ (range, $30-87 \%$ ).

There was an overall improvement in the range of motion arc from $35^{\circ}\left(\right.$ range $\left.0^{\circ}-160^{\circ}\right)$ to $103^{\circ}$ (range $53^{\circ}-150^{\circ}$ ) at final postoperative follow-up $(p<0.001)$. Linear regression analysis revealed that neither age, lag time from injury to surgery, lag time from first visit to surgery, nor postoperative follow-up time had a statistically significant impact on change from preoperative to final arc of flexion-extension. 
Citation: Salazar D, Hill B, Israel D, Aghdasi B, Andrew Golz BS, et al. Elbow Heterotopic Ossification Excision in Patients with Worker's Compensation Claims. J Orthopedics Rheumatol. 2018; 5(1): 6.

The dichotomous variables of gender, tobacco usage, diabetes, performance of intraoperative capsulotomy/partial capsulectomy, performance of intraoperative anterior ulnar nerve transposition, and side of involved extremity also did not demonstrate a statistically significant effect on change from preoperative to final arc of flexionextension motion. Only hypertension and obesity (defined as BMI greater than 30) demonstrated a statistically significant effect on change from preoperative to final arc of motion $(p<0.02$, and $p<0.001$ respectively).

Comparison of patient demographics of the worker's compensation and non-worker's compensation groups seventeen elbows (37\%) had worker's compensation claims, while $29(63 \%)$ had private medical insurance, Medicaid, or Medicare. When comparing the two groups, there was no statistically significant difference with regard to tobacco usage ( $p=0.6)$, diabetes $(p=0.6)$, obesity $(p=0.5)$, hypertension $(p=0.4)$, coronary artery disease $(p=0.6)$, peripheral vascular disease $(p=0.6)$, or chronic obstructive pulmonary disease $(p=0.4)$ between the two groups. There was a statistical difference with regard to gender ( $p=0.007$ ), as the workers compensation group was comprised of 16 men and 1 woman, and the other insurance group was comprised of 16 men and 13 women (Table 1 ).

There was no statistical difference in time from injury $(p>0.05)$ or initial outpatient visit $(p>0.05)$ to surgery or for length of postoperative follow-up $(p>0.05)$ between the two groups. For the worker's compensation group, there was a mean time from injury to surgery of 411 days (range, 134-869), mean time from initial presentation to surgery of 175 days (range, 13-461) and a mean postoperative followup of 16 months (range, 3-52). For the non-worker's compensated

Table 1: Comparison of patient characteristics.

\begin{tabular}{|c|c|c|c|c|c|}
\hline & \multicolumn{2}{|c|}{$\begin{array}{c}\text { Worker's } \\
\text { Compensation }\end{array}$} & \multicolumn{2}{|c|}{$\begin{array}{l}\text { Non-Worker's } \\
\text { Compensation }\end{array}$} & \multirow[b]{2}{*}{$\begin{array}{c}P \\
\text { Value }\end{array}$} \\
\hline & $\begin{array}{c}\begin{array}{c}\text { Number } \\
\text { of } \\
\text { Patients }\end{array} \\
\end{array}$ & $\begin{array}{c}\text { Percentage } \\
\text { (\%) }\end{array}$ & $\begin{array}{c}\text { Number } \\
\text { of } \\
\text { Patients }\end{array}$ & $\begin{array}{c}\text { Percentage } \\
(\%)\end{array}$ & \\
\hline $\begin{array}{l}\text { Total Number of } \\
\text { patients in group }\end{array}$ & 17 & & 29 & & \\
\hline $\begin{array}{l}\text { Gender (Men/ } \\
\text { Women) }\end{array}$ & $16 / 1$ & $94 / 6$ & $16 / 13$ & $55 / 45$ & ${ }^{\mathscr{H}} 0.05$ \\
\hline Smoking & 8 & 47 & 14 & 48 & 0.6 \\
\hline Diabetes & 2 & 12 & 4 & 14 & 0.7 \\
\hline Obesity $^{*}$ & 5 & 29 & 7 & 24 & 0.5 \\
\hline Hypertension & 4 & 24 & 5 & 17 & 0.5 \\
\hline $\begin{array}{l}\text { Coronary Artery } \\
\text { Disease }\end{array}$ & 0 & 0 & 1 & 3 & 0.7 \\
\hline $\begin{array}{c}\text { Peripheral } \\
\text { Vascular Disease }\end{array}$ & 0 & 0 & 1 & 3 & 0.7 \\
\hline $\begin{array}{c}\text { Chronic } \\
\text { Obstructive } \\
\text { Pulmonary Disease }\end{array}$ & 0 & 0 & 2 & 7 & 0.4 \\
\hline $\begin{array}{l}\text { Capsulotomy/ } \\
\text { Capsulectomy }^{* *}\end{array}$ & 10 & 59 & 15 & 52 & 0.5 \\
\hline $\begin{array}{l}\text { Anterior Nerve } \\
\text { Transposition }\end{array}$ & 10 & 59 & 18 & 62 & 0.6 \\
\hline $\begin{array}{c}\text { Post-op } \\
\text { Complication }\end{array}$ & 3 & 18 & 5 & 17 & 0.97 \\
\hline
\end{tabular}

BStatistically significant value

*Defined as a body mass index greater than 30

*Intraoperative performance of elbow joint capsulotomy or partial capsulectomy

${ }^{* * *}$ Intraoperative anterior ulnar nerve transposition was performed patients there was a mean time from injury to surgery of 421 days (range, 34-958), mean time from initial presentation to surgery of 191 days (range, 6-797) and a mean postoperative follow-up of 14 months (range, 2-106) (Table 2).

For the patients with worker's compensation claims, the preoperative flexion-extension arc was $48^{\circ}$ (range $0^{\circ}-135^{\circ}$ ) which improved to a mean flexion-extension arc of motion of $105^{\circ}$ (range, $60^{\circ}-134^{\circ}$ ) at final followup. The final follow-up flexion-extension arc minus the preoperative flexion-extension arc was $56.11^{\circ} \pm 37.74^{\circ}$. For the patients without claims, the preoperative flexion-extension arc was $26^{\circ}$ (range $0-160^{\circ}$ ) which improved to a mean flexion-extension arc of motion of $102^{\circ}$ (range $53^{\circ}-150^{\circ}$ ) at final follow-up. The final follow-up arc minus the preoperative arc was calculated to be $75.93^{\circ} \pm 35.95^{\circ}$. There was no statistical difference between groups with regards to preoperative, intraoperative or postoperative flexion, extension, total arc of motion or final follow-up flexion-extension arc minus preoperative flexionextension arc (Table 3).

For all patients, there was a $17 \%(8 / 46)$ postoperative complication rate. Three patients had clinically significant recurrence of HO that caused motion restrictions, 3 patients experienced postoperative nerve palsies ( 2 ulnar nerve, 1 musculocutaneous nerve), 1 patient had postoperative elbow instability that required reoperation and conversion to a total elbow arthroplasty, and there was 1 patient who presented with a deep surgical wound infection with Methicillinresistant Staphylococcus aureus (MRSA) 6 weeks after surgery. When comparing the patients with worker's compensation claims to those without, there was no statistical difference with regard to rate of postoperative complication ( $p=0.97$ ) (Table 1 and Table 4 ).

\section{Discussion}

Several prior studies have established that patients with worker's compensation claims have higher rates of postoperative noncompliance, longer return to work times, and lower validated outcome scores with regard to a myriad of operative treatments [1-6]. A recent meta-analysis demonstrated the negative influence that the presence of workers' compensation had on patient outcomes following orthopaedic and trauma surgery [21]. This comprehensive, bestevidence report demonstrated that surgery on worker's compensated patients had a 2-fold higher chance of obtaining an unsatisfactory outcome, when compared with non-compensated patients [21]. This lead the authors to conclude that worker's compensation status

Table 2: Comparison of age, time to surgery and postoperative follow-up.

\begin{tabular}{|c|c|c|c|c|c|c|c|c|c|}
\hline & \multicolumn{3}{|c|}{$\begin{array}{c}\text { Worker's } \\
\text { Compensation } \\
\text { Group }\end{array}$} & \multicolumn{4}{c|}{$\begin{array}{c}\text { Non-worker's } \\
\text { Compensation Group }\end{array}$} & \\
\cline { 2 - 11 } & Mean & Min & Max & SD & Mean & Min & Max & SD & P Value< \\
\hline Age (Years) & 44 & 28 & 62 & 13 & 40 & 18 & 71 & 16 & 0.5 \\
\hline $\begin{array}{c}\text { Time from Clinic to } \\
\text { Surgery (Days) }\end{array}$ & 411 & 134 & 869 & 204 & 421 & 34 & 958 & 243 & 0.8 \\
\hline $\begin{array}{c}\text { Time from Injury to to } \\
\text { Surgery (Days) }\end{array}$ & 175 & 13 & 461 & 139 & 191 & 6 & 797 & 192 & 0.9 \\
\hline $\begin{array}{c}\text { Post-operative } \\
\text { follow-up (Months) }\end{array}$ & 16 & 3 & 52 & 15 & 14 & 2 & 106 & 20 & 0.8 \\
\hline
\end{tabular}

"Time elapsed from initial outpatient clinic visit to the date of surgery, rounded to nearest day; " ${ }^{*}$ Time elapsed from date of initial injury to the date of surgery, rounded to nearest day; SD: Standard Deviation 
Citation: Salazar D, Hill B, Israel D, Aghdasi B, Andrew Golz BS, et al. Elbow Heterotopic Ossification Excision in Patients with Worker's Compensation Claims. J Orthopedics Rheumatol. 2018; 5(1): 6.

ISSN: $2334-2846$

Table 3: Comparison of preoperative, intraoperative and postoperative flexion and extension.

\begin{tabular}{|c|c|c|c|c|c|c|c|c|c|}
\hline & \multicolumn{4}{|c|}{ Worker's Compensation Group } & \multicolumn{4}{|c|}{ Non-worker's Compensation Group } & \multirow[b]{2}{*}{$P$ Value $<$} \\
\hline & Mean & Min & Max & SD & Mean & Min & Max & SD & \\
\hline Terminal Preoperative Flexion & 89 & 40 & 135 & 30 & 83 & 10 & 150 & 35 & 0.5 \\
\hline Terminal Preoperative Extension & 42 & 0 & 80 & 21 & 56 & -10 & 72 & 32 & 0.09 \\
\hline Preoperative Arc of Flexion-Extension & 49 & 0 & 135 & 43 & 26 & 0 & 160 & 36 & 0.07 \\
\hline Terminal Intraoperative Flexion & 127 & 90 & 140 & 12 & 127 & 80 & 160 & 15 & 1 \\
\hline Terminal Intraoperative Extension & 13 & 0 & 60 & 16 & 13 & -10 & 40 & 15 & 1 \\
\hline Intraoperative Arc of Flexion-Extension & 114 & 30 & 135 & 25 & 114 & 70 & 170 & 24 & 0.9 \\
\hline Terminal Postoperative Flexion & 120 & 80 & 139 & 17 & 121 & 90 & 155 & 16 & 0.8 \\
\hline Terminal Postoperative Extension & 15 & -4 & 45 & 13 & 0 & 60 & 19 & 17 & 0.5 \\
\hline Postoperative Arc of Flexion-Extension & 105 & 60 & 134 & 23 & 102 & 53 & 150 & 25 & 0.8 \\
\hline Postoperative Arc Minus Preoperative Arc & 56 & -1 & 125 & 38 & 76 & -10 & 130 & 36 & 0.08 \\
\hline
\end{tabular}

All values expressed as degrees; Negative values represent hyperextension of the elbow; SD: Standard Deviation

Table 4: Postoperative complications.

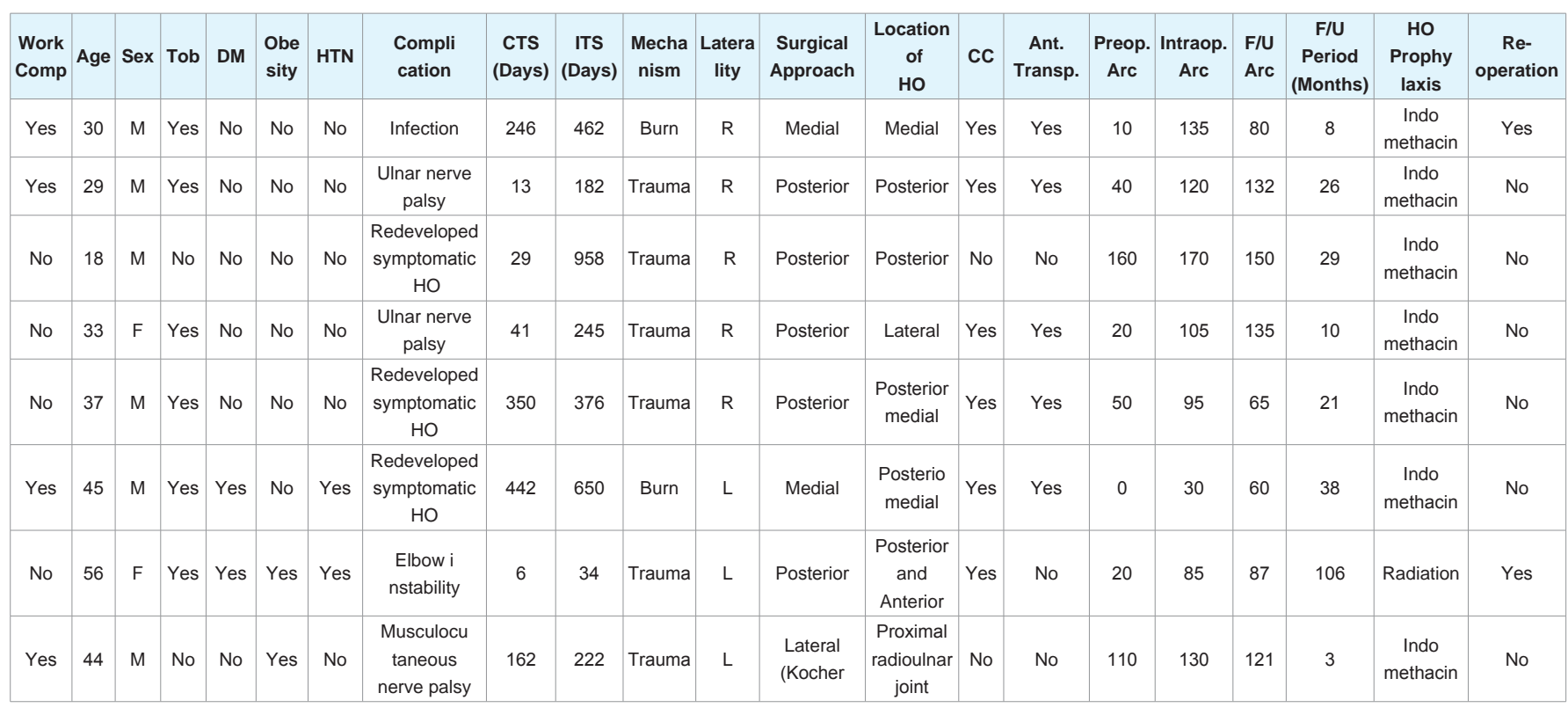

M: Male; DM: Diabetes; PVD: Peripheral Vascular Disease; CTS: Time from First Clinic Visit to Surgery; Ant. Transp: Performance of Intraoperative Anterior Ulnar Nerve Transposition; F: Female; HTN: Hypertension; COPD: Chronic Obstructive Pulmonary Disease; ITS: Time from Injury to Surgery; Arc: Total Flexion-Extension Arc of Motion in Degrees; Tob: History of Smoking; CAD: Coronary Artery Disease; CC: Performance of Intraoperative Capsulotomy/Partial Capsulectomy; HO: Heterotopic Ossification

should be taken into account when surgeons contemplate surgical treatment options. Particular to maladies of the upper extremity, it has been established that worker's compensation patients often have poorer outcomes [1,3,5,7-9]. Specific to other elbow disorders such as distal biceps tendon rupture and lateral epicondylitis, worker's compensated patients have lower validated outcome scores and longer return to work times $[1,7]$. However, the effect of worker's compensation on outcome following surgical excision of $\mathrm{HO}$ about the elbow has never been investigated. The purpose of this study is to retrospectively report on a consecutive series of patients with $\mathrm{HO}$ about the elbow, and to analyze the results of surgical treatment and a standardized postoperative rehabilitation regimen with regards to the presence of a worker's compensation claim.

In our consecutive series, 17 elbows (37\%) had worker's compensation claims, while 29 (63\%) had private medical insurance, Medicaid, or Medicare. Other than patient gender, there was no statistical difference in patient demographics, medical history, time to surgery, rate of intraoperative capsulotomy, rate of ulnar nerve transposition or postoperative follow-up between the group with workers compensation and the group without. Patients with worker's compensation claims increased their flexion-extension arc an average of $56^{\circ}$ compared with $76^{\circ}$ for patients without claims, but this was not found to be statistically significant. Thus, there was no statistical difference in postoperative outcome, as measured by change in flexion-extension arc between the two groups.

The true incidence of $\mathrm{HO}$ about the elbow may be underestimated secondary to most cases being subclinical and not resulting in significant long-term symptoms or permanent impairment [18]. Surgical excision has become the preferred treatment for $\mathrm{HO}$ of the elbow causing functional impairment [13,19,22-31]. Although restoration of normal motion is unlikely, multiple studies have reported improved elbow outcome scores and increased range of motion after operative treatment $[13,16,19,22,29,30,32]$. Classically, functional elbow range of motion for activities of daily living has 
Citation: Salazar D, Hill B, Israel D, Aghdasi B, Andrew Golz BS, et al. Elbow Heterotopic Ossification Excision in Patients with Worker's Compensation Claims. J Orthopedics Rheumatol. 2018; 5(1): 6.

been defined as a functional motion arc of $100^{\circ}\left(30^{\circ}-130^{\circ}\right.$ of flexion and $50^{\circ}$ of pronation to $50^{\circ}$ of supination) [33]. However with the use of 3-dimensional optical tracking technology and the inclusion of more modern tasks, functional activities have recently been shown to require a greater mean flexion arc of 130 degrees [34].

A recent systematic review of outcomes after surgical resection of $\mathrm{HO}$ about the elbow calculated an average gain of $71^{\circ}$ in the flexionextension arc and $40^{\circ}$ of pronation-supination arc [17]. Increased preoperative arc of motion, burn etiology and postoperative CPM use were associated all with improved outcomes [17]. The overall complication rate was found to be $22.6 \%$, with those patients having sustained brain injury having poorer outcomes [17]. In the reported consecutive series of 46 elbows, there was an overall improvement from a mean arc of flexion-extension of $35^{\circ}$ (range $0^{\circ}-160^{\circ}$ ) preoperatively, to a mean of $103^{\circ}$ (range $53^{\circ}-150^{\circ}$ ) at final postoperative followup $(p<0.001)$. Seventeen percent of the patients in our series had complications associated with the surgery.

Previously, Salazar D et al. evaluated the same patients included in this study for modifiable risk factors associated with improved ROM after surgery, compared the ROM gains between patients with complete ankylosis and partially restricted ROM, and to characterize the complications treated with this surgical management and rehabilitation program [20]. In the previously published report, the authors found only hypertension; obesity and transposition of the ulnar artery were associated with worse outcomes. The only modifiable risk factor was transposition. Previously, the authors did not calculate the change in flexion-extension arc between the preoperative and final follow-up measurements. Although this was not found to be significantly different in our cohorts studied, we are able to counsel patients on the realistic outcome goals they may achieve. In an attempt to further delineate which patients should undergo $\mathrm{HO}$ resection about the elbow, the authors of the current study wanted to evaluate the effects of worker's compensation claims on the outcomes following $\mathrm{HO}$ resection about the elbow.

This study is limited by its retrospective nature. However, due to the relative rarity of symptomatic $\mathrm{HO}$ about the elbow necessitating surgical excision, large prospective comparative studies remain unlikely. Although this is study offers a large number of consecutive patients treated with $\mathrm{HO}$ by a single surgeon, we cannot rule out type II error when comparing the outcomes of patients with workers' compensation and those without. We also acknowledge that our findings would be strengthened by the use of validated outcomes scores for elbow function, the inclusion of pronation-supination measurements, data on return to work and long-term follow-up. Further; three patients in the current study received prophylactic radiation instead of non-steroidal anti-inflammatory medications due to a contraindication for their $\mathrm{HO}$ prevention. Due to the wound problems associated with radiation, non-steroidal anti-inflammatory medications are preferred by the senior surgeon but this could present some bias to the results although 2 patients were in the workers compensation cohort that received radiation and one was y were in the non-workers compensation group [20]. Lastly, gender and ethnicity have been identified as potential independent risk factors for HO formation $[11,35]$. The worker's compensation and non-worker's compensation cohorts in this study did have a significantly different percent of male patients and this could be a further confounder for the study. Future studies should be aimed at identifying preventative measures, modifiable risk factors, treatment algorithms and postoperative regimens that maximize improved functional outcomes, patient safety and cost.

\section{Conclusion}

We conclude that surgical management combined with postoperative $\mathrm{HO}$ prophylaxis and a regimented rehabilitation program is a feasible modality for treating patients with heterotopic ossification of the elbow. In our consecutive series of patients, worker's compensation claims did not have a statistically significant impact on outcome, as measured by change in pre and postoperative elbow flexion-extension arc of motion.

\section{References}

1. Atanda A Jr, O'Brien DF, Kraeutler MJ, Rangavajjula A, Lazarus MD, et al. (2013) Outcomes after distal biceps repair in patients with workers' compensation claims. J Shoulder Elbow Surg 22: 299-304.

2. Barrett GR, Rook RT, Nash CR, Coggin MR (2001) The effect of workers' compensation on clinical outcomes of arthroscopic-assisted autogenous patellar tendon anterior cruciate ligament reconstruction in an acute population. Arthroscopy 17: 132-137.

3. Cuff DJ, Pupello DR (2012) Prospective evaluation of postoperative compliance and outcomes after rotator cuff repair in patients with and without workers' compensation claims. J Shoulder Elbow Surg 21: 1728-1733.

4. Denard PJ, Ladermann A, Burkhart SS (2012) Long-term outcome after arthroscopic repair of type II SLAP lesions: results according to age and workers' compensation status. Arthroscopy 28: 451-457.

5. Holtby R, Razmjou H (2010) Impact of work-related compensation claims on surgical outcome of patients with rotator cuff related pathologies: a matched case-control study. J Shoulder Elbow Surg 19: 452-460.

6. Stake CE, Jackson TJ, Stone JC, Domb BG (2013) Hip arthroscopy for labral tears in workers' compensation: a matched-pair controlled study. Am J Sports Med 41: 2302-2307.

7. Grewal R, MacDermid JC, Shah P, King GJ (2009) Functional outcome of arthroscopic extensor carpi radialis brevis tendon release in chronic lateral epicondylitis. J Hand Surg Am 34: 849-857.

8. Namdari S, Green A (2010) Range of motion limitation after rotator cuff repair. J Shoulder Elbow Surg 19: 290-296.

9. Watson EM, Sonnabend DH (2002) Outcome of rotator cuff repair. J Shoulder Elbow Surg 11: 201-211.

10. Mavrogenis AF, Soucacos PN, Papagelopoulos PJ (2011) Heterotopic ossification revisited. Orthopedics 34: 177.

11. Ranganathan K, Loder S, Agarwal S, Wong VW, Forsberg J, et al. (2015) Heterotopic ossification: basic-science principles and clinical correlates. J Bone Joint Surg Am 97: 1101-1111.

12. Abrams GD, Bellino MJ, Cheung EV (2012) Risk factors for development of heterotopic ossification of the elbow after fracture fixation. J Shoulder Elbow Surg 21: 1550-1554.

13. Maender C, Sahajpal D, Wright TW (2010) Treatment of heterotopic ossification of the elbow following burn injury: recommendations for surgical excision and perioperative prophylaxis using radiation therapy. J Shoulder Elbow Surg 19: 1269-1275

14. Nauth A, Giles E, Potter BK, Nesti LJ, O’Brien FP, et al. (2012) Heterotopic ossification in orthopaedic trauma. J Orthop Trauma 26: 684-688.

15. Garland DE (1991) A clinical perspective on common forms of acquired heterotopic ossification. Clin Orthop Relat Res: 13-29.

16. Gaur A, Sinclair M, Caruso E, Peretti G, Zaleske D (2003) Heterotopic ossification around the elbow following burns in children: results after 
Citation: Salazar D, Hill B, Israel D, Aghdasi B, Andrew Golz BS, et al. Elbow Heterotopic Ossification Excision in Patients with Worker's Compensation Claims. J Orthopedics Rheumatol. 2018; 5(1): 6.

excision. J Bone Joint Surg Am 85-A: 1538-1543.

17. Lee EK, Namdari S, Hosalkar HS, Keenan MA, Baldwin KD (2013) Clinical results of the excision of heterotopic bone around the elbow: a systematic review. J Shoulder Elbow Surg 22: 716-722.

18. Summerfield SL, DiGiovanni C, Weiss AP (1997) Heterotopic ossification of the elbow. J Shoulder Elbow Surg 6: 321-332.

19. Baldwin K, Hosalkar HS, Donegan DJ, Rendon N, Ramsey M, et al. (2011) Surgical resection of heterotopic bone about the elbow: an institutional experience with traumatic and neurologic etiologies. J Hand Surg Am 36: 798-803

20. Salazar D, Golz A, Israel H, Marra G (2014) Heterotopic ossification of the elbow treated with surgical resection: risk factors, bony ankylosis, and complications. Clin Orthop Relat Res 472: 2269-2275.

21. de Moraes VY, Godin K, Tamaoki MJ, Faloppa F, Bhandari M, et al. (2012) Workers' compensation status: does it affect orthopaedic surgery outcomes? A meta-analysis. PLoS One 7: e50251.

22. Brouwer KM, Lindenhovius AL, de Witte PB, Jupiter JB, Ring D (2010) Resection of heterotopic ossification of the elbow: a comparison of ankylosis and partial restriction. J Hand Surg Am 35: 1115-1119.

23. Chao EK, Chen AC, Lee MS, Ueng SW (2002) Surgical approaches for nonneurogenic elbow heterotopic ossification with ulnar neuropathy. J Trauma 53: 928-933.

24. Garland DE (1998) Early excision of heterotopic ossification about the elbow followed by radiation therapy. J Bone Joint Surg Am 80: 453-454.

25. Garland DE, Hanscom DA, Keenan MA, Smith C, Moore T (1985) Resection of heterotopic ossification in the adult with head trauma. J Bone Joint Surg Am 67: 1261-1269.
26. Hunt JL, Arnoldo BD, Kowalske K, Helm P, Purdue GF (2006) Heterotopic ossification revisited: a 21-year surgical experience. J Burn Care Res 27 $535-540$.

27. Keschner MT, Paksima N (2007) The stiff elbow. Bull NYU Hosp Jt Dis 65: 24-28.

28. McAuliffe JA, Wolfson AH (1997) Early excision of heterotopic ossification about the elbow followed by radiation therapy. J Bone Joint Surg Am 79: 749-755.

29. Park MJ, Chang MJ, Lee YB, Kang HJ (2010) Surgical release for posttraumatic loss of elbow flexion. J Bone Joint Surg Am 92: 2692-2699.

30. Ring D, Jupiter JB (2003) Operative release of complete ankylosis of the elbow due to heterotopic bone in patients without severe injury of the central nervous system. J Bone Joint Surg Am 85-A: 849-857.

31. Ring D, Jupiter JB (2004) Excision of heterotopic bone around the elbow. Tech Hand Up Extrem Surg 8: 25-33.

32. Tsionos I, Leclercq C, Rochet JM (2004) Heterotopic ossification of the elbow in patients with burns. Results after early excision. J Bone Joint Surg $\mathrm{Br} 86$ : 396-403.

33. Morrey BF, Askew LJ, Chao EY (1981) A biomechanical study of normal functional elbow motion. J Bone Joint Surg Am 63: 872-877.

34. Sardelli M, Tashjian RZ, MacWilliams BA (2011) Functional elbow range of motion for contemporary tasks. J Bone Joint Surg Am 93: 471-477.

35. Davis G, Patel RP, Tan TL, Alijanipour P, Naik TU, et al. (2016) Ethnic differences in heterotopic ossification following total hip arthroplasty. Bone Joint J 98-B: 761-766. 